\title{
SYMPOSIUM COMPLEXITIES OF SOCIAL KNOWLEDGE STRUCTURE
}

\author{
Held at the 30th Annual Meeting of the Psychonomic Society \\ November 1989, Atlanta, Georgia
}

Chaired by Steven J. Sherman, Indiana University

Social psychology has been an interstitial field since its founding at the turn of the century. On the one hand, it is a conduit through which the theories and findings of experimental psychology are extended, applied, and tested in naturally occurring tasks that involve perception, memory, and decision. On the other hand, it is a conduit back into experimental psychology for important, complex phenomena and, occasionally, theoretical insights. The contributions to this symposium summarize recent results from social cognition research on self-, interpersonal, and group judgment, and on attitudes that pose challenges for simple theories of knowledge representation or theories of categorization based only on similarity or on feature correlations. At the same time, some of these results concerning "naive theories" of social entities, emotional processes invoked by certain judgments, and conscious versus unconscious information processing have been anticipated by the most recent developments in experimental psychology. 